\title{
Setting expectations: Building the blocks of phonemic awareness
}

\author{
W. L. Quint Oga-Baldwin, Waseda University \\ Kaori Nakao, Seinan Gakuin University \\ Luke K. Fryer, University of Hong Kong
}

\begin{abstract}
Young learners require developmental benchmarks to improve awareness of the phonemes in a new language. This study aimed to extend our understanding of Japanese elementary school students' general and specific phonemic awareness across four years of English instruction. A public elementary school $3^{\text {rd }} 6^{\text {th }}$ year students in Japan $(n=261$, ages $=8-12)$ participated in this study. The phonemeidentity test used consisted of fifteen items employing words during students' regular English classes. The effect of year on achievement and the difference between grades was tested. There was a significant effect of students' year on test score $(p<.05)$. While there were no statistically significant difference years $4-5$, and between years 5-6, students' phonemic awareness increased two-year increments. Moreover, patterns of specific phoneme difficulties were identified. The present study provides preliminary guidelines for understanding the intersection between first and foreign languages, instructional context and their shared contribution towards listening and reading development in primary schools.
\end{abstract}

\section{Introduction}

\section{Phonemic awareness and language expectations}

Learning to read in a foreign language requires some degree of mastery of the phonology of the new language (Melby-Lervåg and Lervag 2014). For children who have developed literacy in one language, linguistic expectations from that language can interfere with children's acquisition of the new language (van Daal and Wass 2017); thus learning to read in an alphasyllabic language after learning a non-alphasyllabic one requires connecting the sounds to the letters and symbols of the new language (McBride-Chang et al. 2013). Across alphasyllabic languages, children who fail to acquire awareness of the system of phonemes and the letter sound connections continuously struggle with literacy (Moll et al. 2014). As such, phonemic awareness can be understood as a critical element of foreign language acquisition for learning to ready in English, necessary but not sufficient to explain ultimate attainment of literacy. Young learners learning to read English and other alphabetic languages thus require standards and 
developmental benchmarks for improving awareness of the phonemes in the new language.

Researchers have suggested a number of universals when learning to read in an alphasyllabary such as English (Nag and Snowling 2012). Given that reading in any language involves some degree of phonological processing (Leininger 2014), reading appears to stand firmly based on general language skills, which include vocabulary knowledge, oral language ability, and understanding of the phonology language (Hulme et al. 2020). Connection between sounds and letters is a necessary step in learning to read in most European languages involving an alphasyllabary (Moll et al. 2014). As a result, the process of learning to read in a new language can be understood to some extent as mapping a new set of phonemic principles onto written characters. However, recognizing that expectations and conventions from students' own language may impede students acquisition of the new language (Ellis, 2005), the process by which this mapping occurs requires careful consideration of the local language environment.

\section{Japanese curriculum and reading acquisition}

In 2017, the Japanese Ministry of Education, Culture, Sports, Science and Technology [henceforth MEXT] expanded the curriculum: what had been once-aweek foreign language activities became a twice-a-week formal subject of study for fifth and sixth grades students, with third and fourth graders now getting one lesson each week (MEXT 2017). Upper elementary has become focused on the comprehensive teaching and learning of four-skills (i.e., listening, reading, speaking, and writing). According to the current Course of Study (MEXT 2017), students are expected to be able to write uppercase and lowercase letters in block type, and to be able to copy out familiar oral expressions. Importantly, though MEXT is clear regarding the difficulties Japanese students face in acquiring literacy (MEXT, 2017 p. 7), no standard tools or methods have been put forth to assess students' growth and development for the Japanese curricular environment.

According to Japanese linguistic theory, the base sound unit of the Japanese language is the syllable-like unit called the mora (Tsujimura 2014). Mora units 
almost universally consist of a voiced vowel sound, in most cases preceded by a consonant sound (e.g., $k a, s a, t a$ ) and rarely ending in a consonant sound. It is thought that Japanese children in learning their own language develop mora awareness, but do not develop phonological awareness for units smaller than the mora naturally without instruction in other language sound systems (Tsujimura, 2014). MEXT (2017) has recognized several challenges to learning English, one of which is the difference between the Kunrei-style Romanization of Japanese mora taught in most schools and standard uses of English (Tsujimura 2014). The Kunrei-style spelling conventions used to teach Romanization follow regular rules (e.g., sa, si, su, se, so, ta, ti, tu, te, to) but do not conform to standard representations of sounds used in other alphabetic languages (e.g., the [ $\mathrm{t} \mathrm{f}]$ phoneme is represented as $t i$ in Kunrei-style, while more standard English would regularly represent this with chi). There is thus considerable potential interference between children's own language conventions and English.

According to Inoue (2017), Japanese learners process the kana writing system as primarily phonological, mapping the largely transparent orthography according to consistent aural rules. This procedure mirrors literacy development in languages with transparent orthographies, such as Finnish, German, and the Scandinavian languages (Moll et al. 2014). In contrast, the kanji system appears to be processed through the phenomenon of Rapid Automatic Naming (RAN), where phonemically opaque characters with specific individual meaning are mapped through memorization, association, and recall. This finding largely mirrors learning processes in other character based systems, such as Chinese (McBride-Chang et al. 2013). English contains similar elements of transparent and opaque orthography. Studies of literacy development consistently indicate that learning to read English texts involves a process of both phonemic decoding and awareness as well as rapid automatic naming (Castles et al. 2018).

These prior research findings indicate that, despite the surface level differences between English and Japanese with regard to phonology and writing conventions, the process by which literacy is gained in both languages is ultimately similar: an automatized reading of opaque/semi-opaque meaningfocused words standing alongside a phonemically based sound-character 
structure that assists in the learning the readings of the commonly used words. Thus, for this and other similar settings, a clear process for understanding and assessing the development of phonological awareness might provide a clearer picture of how to improve learners' literacy skills in their new language. Despite the potential for linguistic interference (van Daal and Wass 2017) based on Japanese students' own language learning practices and the conventions of Romanization, no systematic hypothetical model for the development of soundletter phonemic connections has been empirically verified in this context.

By successfully trial of the current study's instrument, previous research has provided proof-of-concept for assessing young language learners' phonemic awareness of English in input-poor monolingual environments (Nakao et al. 2021). The current research extends this field of inquiry to develop a set of predictive hypotheses based on the linguistic features of students' own language to help identify which sounds and their alphasyllabic representations require extra attention for learners first exposed to English as a new language. We replicate previous methodologies and findings (Bradley and Bryant 1983), while extending the analyses to demonstrate potential phonemic difficulties that learners experience. Further, the study was conducted immediately after the reopening of schools after the 2020 school closings due to COVID-19, providing evidence not only for the importance of exposure generally for helping improve students' learning, but also for the role of schools for delivering learning content that students cannot be expected to get in their natural living environments. Based on previous findings and the need to develop testable developmental hypotheses for the acquisition of phonemic awareness in learning English, we investigated a cohort of young Japanese learners' phonemic awareness of English across four grades.

\section{Aims}

Building on a foundation of phonemic awareness (Bradley and Bryant 1983) research and a previous pilot study (Nakao et al. 2021) in the same school context, this study is aimed to extend our understanding of Japanese elementary school students' general and specific phonemic awareness across their four year 
of English instruction (years three to six). We sought to answer the following research question and confirm the following hypothesis.

Research Question One (RQ1): What is the difference in elementary school students' specific phonemic awareness across the four year of nationally mandated curricula (years three-six)?

Hypothesis One (H1): Following principles of Japanese phonology (Tsujima, 2014), children were expected to have stronger phonemic awareness of English phonemes that corresponded directly to the expression of Japanese Kunrei-style spelling in a one-to-one manner (henceforth direct-quick; e.g., $m, k$ ). Students were expected to have moderate phonemic awareness of English phonemes which have multiple correspondences with Japanese Kunrei-style (henceforth multiple-delayed; e.g., $l, r$ ). Students were expected to have low phonemic awareness of English sounds / letters which did not have a correspondence in the Kunrei-style (henceforth unrepresented-slow; e.g., $q, v$ ).

\section{Methods}

\section{Participants}

Public elementary schools' students in Western Japan (total $n=261$, female $n=138$ ) participated in this study. All participating students were between eight and twelve years old. Students in each grade were taught under the same curriculum progression. All elementary schools in Japan were closed from March to May due to COVID-19. The 3rd and 4th grade students engaged in English language activities class once-a-week, while 5th and 6th grade students studied English as a formal subject twice-a-week, beginning in July 2020. Due to the pandemic, class hours for the first semester were shortened. A Japanese teacher of English who worked at this school collaborated with the researchers to conduct tests. All participating classes were taught by this teacher.

Data gathering occurred at a small-medium sized school in the suburbs of a large Japanese city in western Japan. The assessment was administered in the first semester of the 2020 school year during regular foreign language classes. Ethical 
oversight was included in the review process for JSPS Grant-in-aid for Scientific Research $<$ Grant number removed for peer review $>$. All procedures were in accordance with the ethical standards of the national research committee.

\section{Procedure}

\section{Instruments}

The phoneme-identity test used in this study consisted of fifteen items employing words, selected from the third grade assigned Ministry textbook (MEXT 2017). An optical mark reader (OMR) sheet was used for students' to report their answers, with letter A to Z, and ? for 'I don't know' presented as choices (See Appendix 1). Capital letters were used to increase students' recognition and ease of report. Previous studies using this testing format have indicated students with a stronger recognition of initial sounds have better PA (e.g., Melby-Lervåg and Lervåg 2014). The test confirmed results from the pilot study conducted six months prior (Nakao et al. 2021).

The PA test was administered by the native Japanese teacher of English who taught at the elementary school where the study took place. The participating teacher pronounced each of the fifteen words twice with no specific emphasis on any syllable. The participating teacher participated in a brief training on how to read alphabet word by the first author. The students selected the letter on the test sheet after hearing each of the fifteen target words. The teacher distributed and collected test papers for all classes. The test took between seven and fifteen minutes to complete.

Tests were conducted in July of the 2020 school year. This timing provides context for the role instruction can play in students' phonemic awareness. Given that students were unlikely to receive daily English input and exposure in their daily lives (MEXT, 2017), any year to year gains can thus be inferred as stemming from school instruction.

Tests were scanned and converted to data using OMR software. The first author reviewed each scan to address marking errors and input mistakes. The finalized data was imported to JMP14.1 (SAS Inc., 2019) for analysis. 


\section{Analysis}

An analysis of variance (ANOVA) test using students' grade as the independent variable (IV) and students' success for phonemic awareness item as the dependent variable (DV) was conducted to determine whether students differed in their specific phonemic awareness across grades. A probability analysis (Grade $\mathrm{x}$ Phonemic Item success) was then conducted to examine success rate for students from each grade for each phonemic item.

\section{Results}

The test presented sufficiently normal distribution of scores: skew was approximately symmetric ( -1 to 1 ) and kurtosis within reasonable limits ( -2 to 2 ; George and Mallery, 2010). Table 1 presented the descriptive statistics with skew and kurtosis for each grade. A one-way between subjects ANOVA (H1) compared the effect of (IV) year of study on (DV) test score. There was a significant effect of IV year of study on DV test score at the $p<.05$ level for the three conditions $[F(3,261)=42.36, p<.0001]$. Given the simple nature of the test, year of study accounted for a considerable amount of the difference in students' test scores $\left(R^{2}=.33\right)$. A Tukey-Kramer HSD post hoc test (H1) was significant $\left(\mathrm{q}^{*}=2.59\right.$, Alpha $\left.=.05\right)$. Results suggested that there was no statistically significant difference years 4 and 5 , and between years 5 and 6 , but that students' phonemic awareness increased in two year increments.

Table 1. Means, Standard Deviation, Sample size by Grade

\begin{tabular}{lllll}
\hline Grade & 3 & 4 & 5 & 6 \\
\hline Mean & 2.78 & 7.06 & 8.2 & 9.34 \\
Std Dev & 2.74 & 3.73 & 3.93 & 4.12 \\
$\mathrm{~N}$ & 68 & 67 & 62 & 64 \\
\hline
\end{tabular}


Table 2. ANOVA of Stepwise differences in test scores across grades.

\begin{tabular}{lllllll}
\hline Predictor & Sum of Squares & $d f$ & Mean Square & $\mathrm{F}$ & $p$ & $\mathrm{R}^{2}$ \\
\hline grade & 1699.7987 & 3 & 566.600 & 42.3626 & $<.001$ & 0.33 \\
Error & 3437.3737 & 257 & 13.375 & & \\
Total & 5137.1724 & 260 & & & & \\
\hline
\end{tabular}

Table 3. Probability of Phonemic Awareness Success Pattern across Years

\begin{tabular}{|c|c|c|c|c|c|c|}
\hline \multicolumn{2}{|c|}{ Hypothesized progress } & \multicolumn{5}{|c|}{ Actual Progress } \\
\hline $\begin{array}{l}\text { Direct Multif } \\
\text { Quick Delay }\end{array}$ & $\begin{array}{l}\text { Unrepresented } \\
\text { Slow }\end{array}$ & Ceilin & Immed & Annual & Deferred & Floored \\
\hline Elephant Bear & Question & Orange & Koala & Bear & Red & Umbrella \\
\hline Friend Lemon & Umbrella & & Tiger & Friend & Question & \\
\hline Game Red & Violin & & Elephant & Game & & \\
\hline Jam & & & & Jam & & \\
\hline Nose & & & & Lemon & & \\
\hline Orange & & & & Nose & & \\
\hline Tiger & & & & Violin & & \\
\hline Winter & & & & Winter & & \\
\hline
\end{tabular}



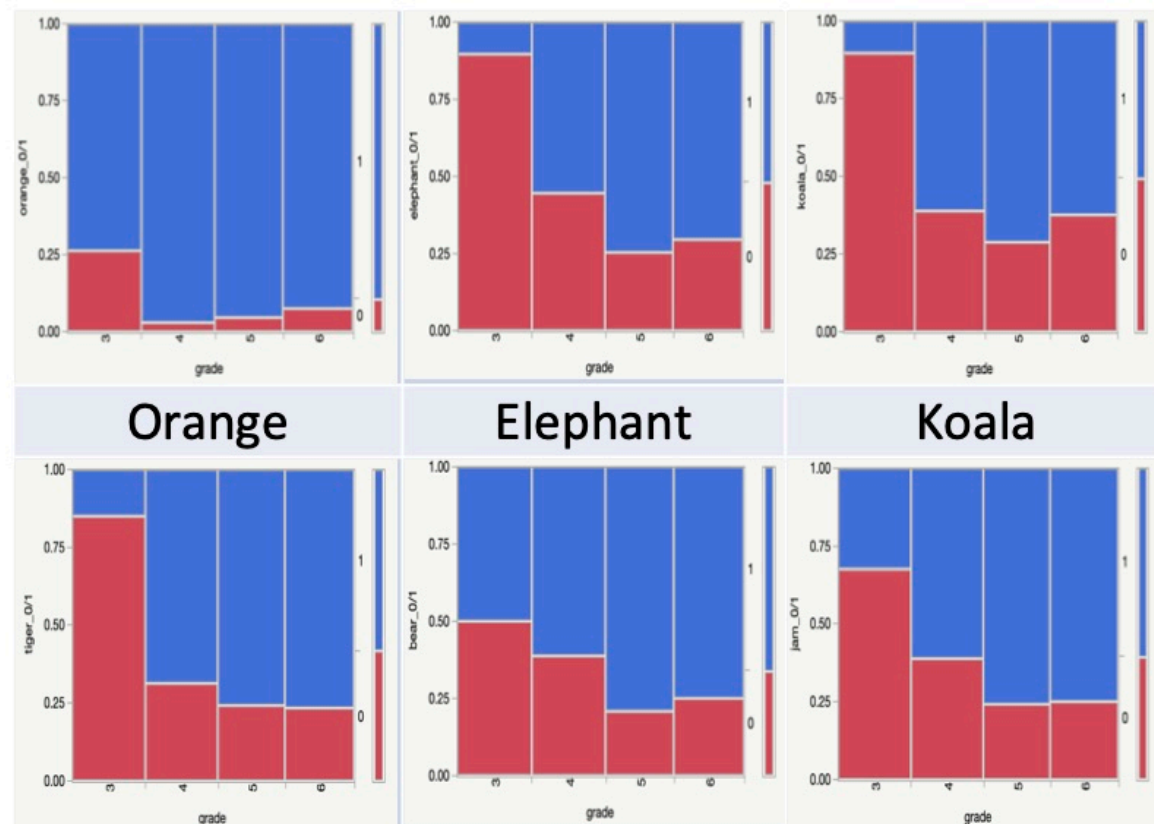

Koala

Tiger
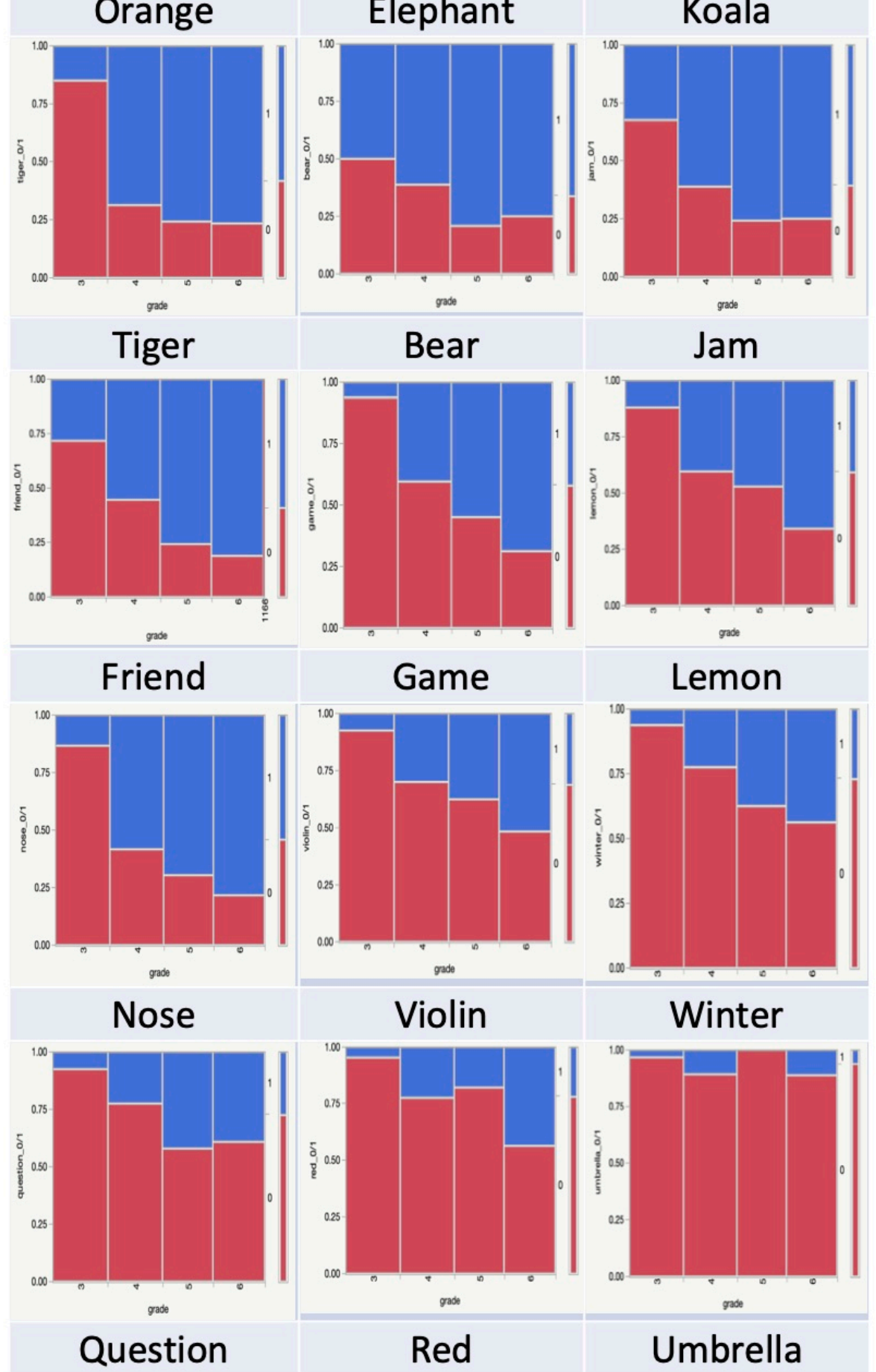

Figure 1. Answer probabilities by grade. Blue $=$ Correct, Red $=$ Incorrect . 
The ANOVA of the 15-item test (DV) and student year (IV) indicated significant, and substantial $\left(\mathrm{R}^{2}=.33\right)$ differences in students' knowledge across the four different years assessed. Pair-wise testing between years of study indicated no differences between two sequential cohort (years 4-5 and years 5-6) but differences across the two-year gaps. Chi-Square test were conducted for each phoneme by students' grade (RQ2). All 15 tests indicated significant differences $(p<.01)$ across the four grades. Figure 1 present the graphical results of the probability analyses for each phoneme by students' grade. The pattern of probability for phonemic awareness students' success by year on each of the 15item tests across the two samples was examined. This pattern mirrored the results from the previous pilot study of the instrument (Nakao et al. 2021). This review was undertaken in reference to the organisation framework of English to Japanese phonemic awareness correspondence presented previously: DirectEasy (e.g., T), Multiple-Delayed (e.g., B); Unrepresented-Slow (e.g. Q). This interpretive framework was found to represent the data poorly, and thus an alternative framework is here proposed. Table 2 presents both the individual phoneme awareness items organised in the framework, the resulting pattern of categories of students' actual progress across the cohorts (years 3-4-5-6) and samples tested.

Figure 1 displays the resulting pattern of achievement. The findings more accurately indicated five categories of progress across the four years assessed. The re-interpretation of the difficulty of each item is based on the total pattern of right answers as well as the shape of the distribution of correct vs. incorrect answers across years. The five resulting categories of phonemic awareness progress were 1) Ceilinged progress, indicated by a high degree of answer accuracy from the first year of study; 2) Immediate progress, indicated by a high number of wrong answers in the first year, with strong improvement in the following years; 3) Annual progress, showing steady stepwise improvement across all four years; 4) Delayed progress, showing difficulty in the first years but improvement later; and finally, 5) Floored progress, showing no meaningful progress in phonemic awareness across the four cohorts tested.

Ceilinged progress was represented only by the initial [o] sound, represented by the word orange. Students showed Immediate progress on the relatively 
transparent $[\mathrm{t}]$ and [k] sounds, represented by the words tiger and koala, respectively, as well as the relatively frequent $[\varepsilon]$ found in elephant. Students showed Annual progress on the majority of initial sounds. Phonemes with Delayed progress were those with weaker representation in Japanese, such as the rhotic $[\mathrm{r}]$ as in red and the graphemically irregular question. Finally, the complex vowel [ə] represented in the word umbrella was the most difficult of all to acquire, with few students in any grade able to correctly identify the soundletter connection.

\section{Discussion}

The current study examined general and specific differences in phonemic awareness across four years of Japanese elementary school with a crosssectional, cohort design. In addressing specific differences, data from prior pilot study (Nakao et al. 2021) were drawn upon as a source of triangulation for the patterns observed. Toward these aims the current study addressed one research question and one hypothesis. Confirming results from a previous study the current study indicated statistically significant differences in general phonemic awareness across the four grades tested (RQ1). Failing to confirm our hypothesis (H1) statistically significant differences were not observed annually, but were observed across multiple years. Substantial differences were observed across years of study for students' phonemic awareness of specific phonemes.

Probability analysis of the present data set and data from a prior study indicated a pattern of phonemic awareness development that somewhat overlapped with this study's initially proposed framework (direct, multiple, and unrepresented), but required additional practical consideration for the instructional and cultural context.

An individual probability analysis of students' overall correct answers for each item indicated that certain sounds were markedly easy to identify, with students at younger grades very quickly able to identify the corresponding sound (e.g., $o$ for orange), while others were not acquired even by students in the top grade (e.g., $u$ for umbrella). These items fit a pattern we have labelled ceilinged and floored progress, as they occur at the top and bottom of the distributions and do not show significant movement. A small number of items (e.g., $k$ for koala) 
showed immediate progress, and were answered correctly by a majority of students in the first year, with increases each successive year. Most items (e.g., $[n]$ for nose, [I] for lemon) showed annual progress, with a stepwise increase in the number of students each year able to correctly identify the sound-letter connection. Finally, some items demonstrated deferred progress, with no noticeable growth until the final year of elementary school (notably, [r] for $r e d$ ). These findings allow for the development of future hypotheses regarding the potentially hierarchical nature of phoneme difficulties, based to some extent on the hypothesized framework of letters representing sounds regularly found in students' own language (direct; i.e, $g, t, j$ ), sounds with multiple representations in English but only a single representation in Japanese (multiple; i.e. [ə] for any vowel), and sounds with no representation in Japanese.

As a final consideration, the current testing was undertaken after the lockdowns and school closings necessary during the COVID-19 crises of 2020. The generally lower scores for students in $3^{\text {rd }}$ grade are indicative of the lack of English input they received during the abbreviated school year to date, and shows the importance of regular instruction for improving foreign language skills. Likewise, the general improvements shown by fourth- through sixth-graders not only generally but for each phoneme as well further indicate that regular exposure can improve learning.

\section{Practical implications}

For teachers providing initial literacy instruction to young learners, this analysis provides insight into where to expect acquisition difficulties. The current analysis highlights areas of difficulty for young Japanese learners of English, currently every child in Japan above the age of eight years old, and offers teachers in this context heuristics for classroom planning; 1) phonemes found in a child's own language will require little focus for students to acquire them and thus may need little to no explicit teaching; 2) the majority of phonemes show annual progress even without special attention; 3) certain phonemes do not show significant improvement without special attention and are unlikely to be acquired without explicit instruction. Students may see more benefit from increased instruction for the latter of these cases. This framework may thus provide instructors with a clear guideline for how to spend instructional time for 
young learners in their context.

The current study also provides an example of how to do this kind of diagnostic testing across contexts. Instructors wishing to find the areas of greatest instructional need may benefit from a replication of these testing methods for their specific teaching situation. While the current result is keyed to the Japanese instructional setting, teachers of young learners in other regions and areas can conduct similar tests and interpret results with a similar framework when conducting needs analyses of children acquiring English literacy in diverse settings.

\section{Conclusion}

This paper has presented teachers of young learners with a set of practical hypotheses and the methods to confirm them to improve instructional efficacy. By setting pedagogical expectations for students' knowledge and the difficulties they face in acquiring sound-letter connection awareness in a new language across multiple years, we offer teachers a clear guideline for where to spend effort to improve students' reading, listening, and ultimate communication skills. Through a balanced approach to listening, reading, and the explicit connections between letters and sounds, teachers may build a foundation for success in learning a new language beyond the elementary school years.

\section{References}

Bradley, L., and P. E. Bryant. 1983. Categorizing sounds and learning to read-A causal connection. Nature 301: 419-421.

Castles, A., K. Rastle, and K. Nation. 2018. 'Ending the reading wars: Reading acquisition from novice to expert'. Psychological Science in the Public Interest, 19/1: 5-51. http://doi.org/10.1037/0033-2909.123.2.162

George, D. and P. Mallery. 2010. SPSS for Windows Step by Step: A Simple Guide and Reference, 17.0 update (10th ed.) Boston: Pearson.

Hulme, C., M. J. Snowling, G. West, A. Lervåg, and M. Melby-Lervåg. 2020. 'Children's language skills can be improved: Lessons from psychological science for educational policy'. Current Directions in Psychological Science, 29/4: 372-377. 
http://doi.org/10.1111/1460-6984.12339

Inoue, T., G. K. Georgiou, N. Muroya, H. Maekawa, and R. Parrila. 2017. 'Cognitive predictors of literacy acquisition in syllabic Hiragana and morphographic Kanji'. Reading and Writing, 30/6: 1335-1360. http://doi.org/10.1007/s11145-017$9726-4$

Leinenger, M. 2014. 'Phonological coding during reading'. Psychological Bulletin, 140/6: 1534-1555. http://doi.org/10.1037/a0037830

McBride-Chang, C. A. 2016. 'Is Chinese special? Four aspects of Chinese literacy acquisition that might distinguish learning Chinese from learning alphabetic orthographies'. Educational Psychology Review 28/3: 523-549.

https://doi.org/10.1007/s10648-015-9318-2

Melby-Lervåg, M., and A. Lervåg. 2014. 'Reading comprehension and its underlying components in second-language learners: A meta-analysis of studies comparing first- and second-language learners'. Psychological Bulletin. http://doi.org/10.1037/a0033890.supp

MEXT. 2017. Shogakkou gakushuu shidou youryou kaisetu: Gaikokugokatsudou / gaikokugohen [Elementary school curriculum guidelines: Foreign language activities / foreign language]. Retrieved August 2, 2018, from https://www.mext.go.jp/content/20201029-mxt_kyoiku01-100002607_11.pdf

Moll, K. et al. 2014. 'Cognitive mechanisms underlying reading and spelling development in five European orthographies. Learning and Instruction, 29/C: 6577. http://doi.org/10.1016/j.learninstruc.2013.09.003

Nag, S., and M. J. Snowling. 2012. Reading in an alphasyllabary: Implications for a language universal theory of learning to read. Scientific Studies of Reading, 16/5: 404-423. http://doi.org/10.1037/0033-2909.131.1.3

Nakao, K., W. L. Q. Oga-Baldwin, and L. K Fryer. 2021. Phonemic awareness as fundamental listening skill: A cross-sectional cohort study of elementary foreign language learners. SocArXiv Papers. https://osf.io/preprints/socarxiv/hdf2s/

SAS Inc. 2019. JMP®, Version 14.1. Cary, NC, 1989-2019.

Tsujimura, N. 2014. An introduction to Japanese linguistics (3rd ed.). Chichester, UK: John Wiley and Sons.

van Daal, V. H. P., and M. Wass. 2017. 'First- and second-language learnability explained by orthographic depth and orthographic learning: A "natural" Scandinavian experiment'. Scientific Studies of Reading, 21/1: 46-59. 


\section{Acknowledgement}

This work was supported by Grants-in-Aid for Scientific Research, MEXT to the second author (Activity Start-up, No. 19K23093). We thank the students and teachers of the school that participated in this research and thank Toshiaki ICHII, Yoshimi NISHIMURA, and Hisako YAMAGUCHI for their assistance with testing. 